\title{
Pesticide knowledge and safety practices in farm workers from Tubah Sub-Division, North West Region, Cameroon
}

\author{
Charlie C. Nguemo ${ }^{a}$, Margaret Tita ${ }^{a}$, Mosaad A. Abdel-Wahhab ${ }^{b, 1, *}$ \\ ${ }^{a}$ Department of Biology, Higher Teachers Training College Bambili, University of Bamenda, Cameroon. \\ ${ }^{b}$ Food Toxicology \& Contaminants Department, National Research Center, Dokki, Cairo, Egypt \\ ${ }^{1}$ mosaad_abdelwahhab@yahoo.com (MAA), Tel.: +2 2283 1943; fax: +2 33370931 \\ * corresponding author
}

ARTICLE INFO

Article history

Received June 05, 2019

Revised August 31, 2019

Accepted November 02, 2019

Keywords:

pesticides

knowledge

practice

farmers

Tubah sub-division

Cameroon

\section{ABSTRACT}

This study aimed to evaluate the safety measures practiced by farmers with use of pesticides in Tubah Sub-Division. The data gathered would be useful for drafting policies related to use of pesticides to reduce its effects on human health and the environment. This survey was carried out in November 2016 in Tubah Sub-Division, Mezam Division of the North West region of Cameroon. A structured questionnaire was administered to 120 homesteads of the study area. The results revealed that $94.2 \%$ of the farmers were untrained in pesticide safety measures, $30.8 \%$ did not observe any safety interval before consuming freshly treated crops and $25.8 \%$ did not read instructions on pesticide labels before handling. Fifty five percent of the farmers did not use any protective equipment, $79.2 \%$ practiced careless pesticide disposal, $13.3 \%$ stored pesticides in stores and $7.5 \%$ stored pesticides inside their houses. Eighty percent of the families stored their crops via hanging in the house and smoking the crops, while $10.8 \%$ stored their crops in sealed bins. Water washing followed by removing the outer cover was applied as a crop cleaning procedure prior to cooking or consumption. Major symptoms such as headache, wheezing, dizziness and skin problems were observed in the homesteads. Some environmental changes observed after application of pesticides were damage of nontarget plants and disappearance of insects. It could be concluded that in Bambili, farmers lacked proper knowledge regarding safe handling and use of pesticides and the adverse effects of improper pesticide use to human health and the environment.

This is an open access article under the CC-BY-SA license.

\section{Introduction}

Agriculture is considered one of the most hazardous sectors in the economy (ILO, 2011). It has one of the highest rates of occupational hazards next to construction and mining (Das et al., 2016). The Food and Agriculture Organization (FAO) and the International Labor Organization (ILO) report a sum of 335,000 worldwide fatal workplace-related accidents and about 170,000 deaths per year in agricultural workers (Padilla, 2013). The fatal accident incidence in farmers is double that of other occupations (Das et al., 2016). Farmers are exposed to different hazards responsible for occupational injuries in their line of work (Kaewboonchoo et al., 2015). The toxicological effects of pesticides, fuels and fertilizers along with other organic substances are considered some of the 
most common occupational hazards amongst farmers (Damalas and Koutroubas, 2016; Padilla, 2013).

In modern agriculture, pesticides play an important role in farm productivity and the quality of cultivated crops (Verger and Boobis, 2013). Despite the ability of pesticides to protect crops and secure farmer's profit, they have a negative impact on human health and the environment (Grung et al., 2015; Lerro et al., 2015). Several environmental and occupational exposures occur during the loading, mixing and use of pesticides and through pesticide contact with treated crops (Remoundou et al., 2014). Several reports indicate that exposure to pesticides is associated with health hazards such as birth defects and cancer (Cha et al., 2014; Markel et al., 2015). Unfortunately, most farm workers are unaware of the risks of pesticide use. Farmers need continuous technical training in occupational safety in the use of pesticides including application, protective equipment and safe facilities for pesticide storage (Phung et al., 2013).

In Cameroon, the highest levels of pesticide risk occur in rural agricultural areas where farmers handle more than $70 \%$ of all the pesticides used (Pouokam et al., 2017). Tubah Sub-Division, North West Region of Cameroon is an agricultural area where pesticides are heavily used on crops including maize, tomatoes, cabbages and coffee (Matthews et al., 2003). Numerous health problems have been reported in this community which point to the indiscriminate use of pesticides (Kamga et al., 2013; Gimou et al., 2008). However, little is known on the farmers' basic knowledge of the dangers involved in handling, applying and disposing pesticides. There have been no previous studies in Cameroon on the different storage conditions (temperature, light and relative humidity) that result in the optimal degradation of pesticides used on crops. In general, farmers know very little of the health risks of pesticide use to the consumer. The objectives of the current study were to (1) determine the knowledge levels, awareness and pesticide use practices of farmers in Bambili, Tubah Sub-Division, Mezam Division, Cameroon, (2) evaluate the human health and environmental risks posed due to pesticide use and (3) recommend educational programs to decrease the risks of pesticide use in humans and the environment

\section{Material and methods}

\subsection{Study Area}

The study area was confined to Bambili, Tubah Sub-Division, Mezam Division of the North West Region of Cameroon (Fig. 1). The area is located at latitude $5^{\circ} 99^{\prime} 0^{\prime}$ North and longitude $10^{\circ}$ $15^{\prime} 00^{\prime}$ East. It has a humid tropical climate with an annual rainfall of approximately $2200 \mathrm{~mm}$. The average temperature is $20.67{ }^{\circ} \mathrm{C}$ with an altitude of $900 \mathrm{~m}$ above sea level (Focho et al., 2009). The population in Bambili is 27000 , where $80 \%$ are farm workers.

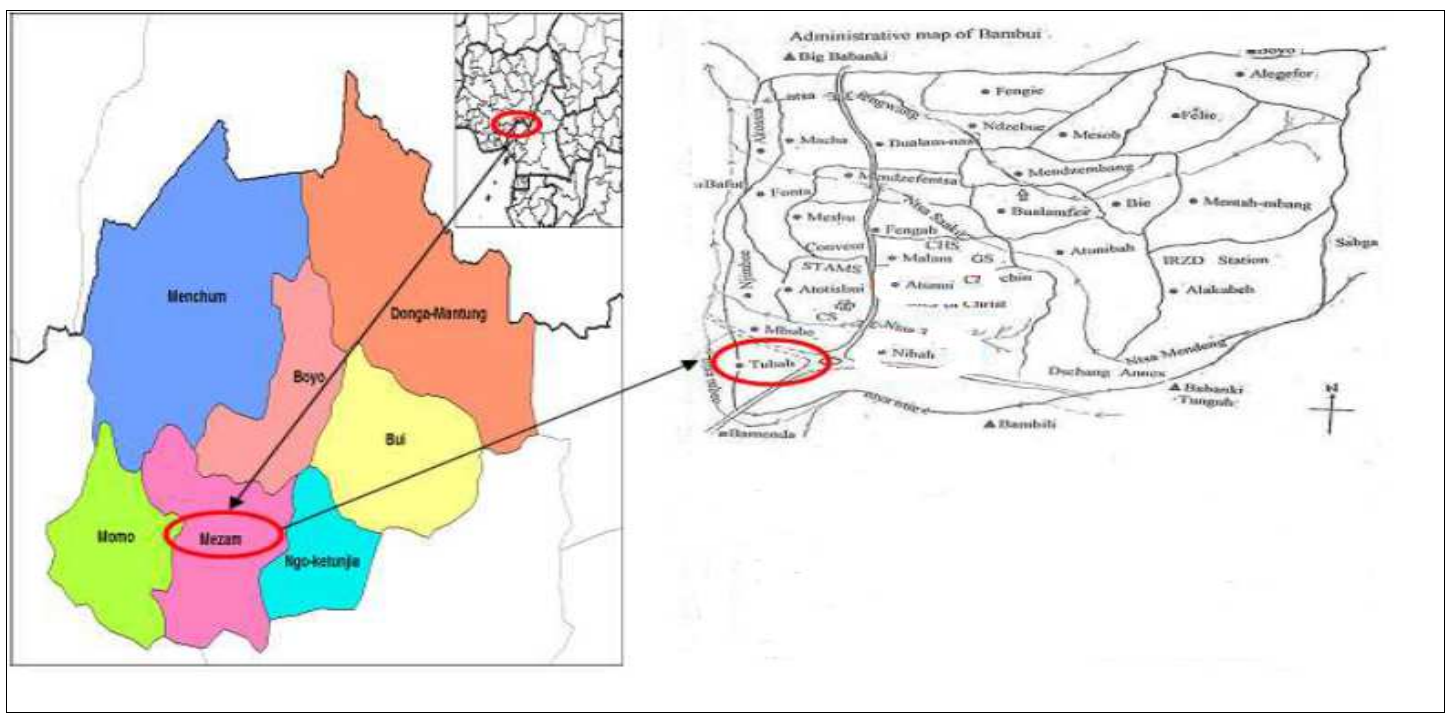

Fig. 1. Map of the study area 


\subsection{Survey instrument}

This survey was conducted using a questionnaire prepared according to the standard format set by Gay (1992) and Mugenda and Mugenda (1999). The questionnaire was administered at random through face-to-face interviews and friendly discussion with homesteads and selected farmers at the study area. The response to each item in the questionnaire was tabulated and its scientific relevance discussed.

\subsection{Methods}

\subsubsection{Questionnaire Administration}

One hundred and twenty households participated in this survey. A home was selected for visit, where the purpose of the study and the importance of the interview was explained. The family head was then issued with the questionnaire to be filled. A research assistant was present to provide clarifications for any questions that the farmers did not understand. For illiterate family heads, the research assistant assisted in filling the questionnaire.

\subsection{Data analysis}

Information from the questionnaire was extracted and tabulated. The data was analyzed to obtain frequencies and percentages for the categorical data. The results are summarized and presented below.

\section{Results}

\subsection{Demographic characteristics of the participants}

120 farmers responded to the survey. Twenty percent of the respondents were male while $80 \%$ were female. The majority of respondents $(59.2 \%)$ had completed primary education, $40.8 \%$ completed secondary education while none of the respondents had any tertiary education. Most of the families $(50.8 \%)$ in the study area were middle-sized with 4 to 7 members; large families with 8 to 12 members accounted for $43.4 \%$ of the respondents, while small families of 1 to 3 members made up $5.8 \%$ of all the families visited. The majority of families $(60.8 \%)$ interviewed settled in small farms of 0 to 5 ha. $39.2 \%$ of the respondents had medium-sized farms of 5 to 10 ha, while none of the families had farms of size 15 ha or more. More respondents (74.2\%) had been farming for more than 10 years while only $25.8 \%$ had been farming for less than 10 years.

At least $5.8 \%$ of the farmers who had participated in the study area had received safety training in handling pesticides, while $94.2 \%$ were untrained. However, $30.8 \%$ of the families confessed that they never observed any safety interval before consuming the freshly treated crops while $69.2 \%$ observed a safety interval. A high number of the farmers (74.2\%) read the instructions on the pesticide labels and adhered to the precautionary advice given while $25.8 \%$ of the farmers however, were not bothered to read the instructions as they were illiterate (Table 3). The majority of farmers $(55 \%)$ did not use any protective equipment while applying pesticides, while $17.5 \%$ used nose guards, $10.8 \%$ used boots, $09.2 \%$ used gloves and $07.5 \%$ used coveralls. None of the farmers used goggles and safety headgears.

$79.2 \%$ of all the pesticide materials were disposed of carelessly and dangerously. In some families (13.3\%), unused pesticides were kept inside stores, while $7.5 \%$ of the respondents kept unused pesticides inside their houses. Disposal of pesticide-related materials through incineration (burning) was not reported in the study area. 
Table 1. Question on farmers' characteristics, knowledge, awareness and risk related to pesticide usage

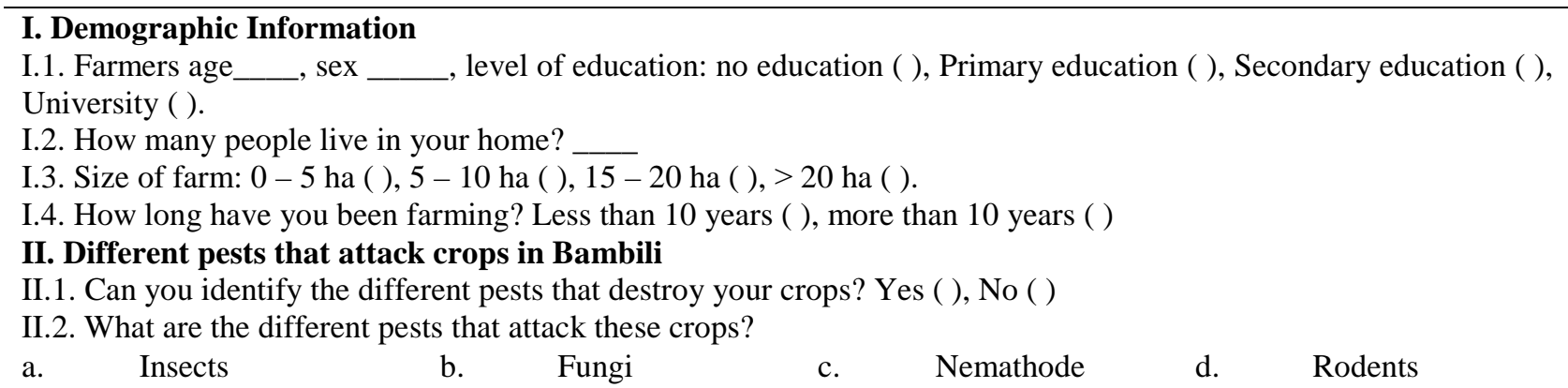

\section{Different types of pesticides used on different types of crops}
Crops
a. Insecticide
b. Nematicide
c. Fungicides
d. Herbicides

1. Vegetables

2. Maize

3. Beans

4. Tubers

5. Groundnut

Others agricultural activities

livestock spraying weed control malaria vector control cash crop (coffee) spraying IV. Farmers' knowledge in pesticide handling, applying and disposing of their containers

1. Have you had any training on how to control pests? Yes ( ) No ( )

2. Do you observe the safety intervals stipulated on pesticide label before consuming the treated crop? Yes ( ) No ( )

3. Do you always read the label on pesticide before using? Yes ( ) No ( )

4. When applying pesticides do you use any safety protective equipment items such as: a. nose guards, b. boots,

c. gloves, d. coveralls, e. goggles, f. headgear, g. none?

5. How do you dispose unused pesticide and empty pesticide containers? Incineration ( ), inside house ( ), inside store ( ), Careless - thrown away ( )

V. Different storage conditions of treated crops

Do you store crops after the harvest? Yes ( ), No ( )

What are your storage facilities?

(i) Traditional granary ___ (ii) Hanging in house and smoking

(iii) Sealed bins (IV) others: say how

VII. Various processing methods in removing pesticide residues from crops before consumption

VII.1. How is the crop prepared prior to cooking? Hulling ( ), Water washing ( ),

Detergent washing ( ), Removing outer cover ( )

VIII. Adverse effect of pesticides in human and his environment

1. Do you experience any adverse effects due to pesticides application on crop? Yes ( ), No ( ).

2. What were the symptoms of these adverse effects? a. Skin problems, b. neurological system disturbances, c. diarrhea, d. vomiting, e. headache, f. dizziness g. wheezing.

3. Have you ever noticed any environmental change after application of pesticides?

Yes ( ) No. ( ) If yes explain how:

Table 2 . Farmer demographic information $(n=120)$

\begin{tabular}{llcl}
\hline Item & Response & $\begin{array}{l}\text { Number of respondents } \\
\text { (frequency) }\end{array}$ & Percentage (\%) \\
\hline Sex & Male & 24 & 20.0 \\
& Female & 96 & 80.0 \\
& Primary & 71 & 59.2 \\
& Secondary & 49 & 40.8 \\
Level of Education & Tertiary & Nil & Nil \\
& $1-3$ & 7 & 5.80 \\
Number of people per & $4-7$ & 61 & 50.8 \\
home & $8-12$ & 52 & 43.4
\end{tabular}




\begin{tabular}{llll}
\multirow{3}{*}{ Size of farm (ha) } & $0-5$ ha & 73 & 60.8 \\
& $5-10$ ha & 47 & 39.2 \\
\multirow{3}{*}{ Length farming } & $15-20$ ha & Nil & Nil \\
& $>20$ ha & Nil & Nil \\
& less than 10 years & 31 & 25.8 \\
& More than 10 years & 89 & 74.2 \\
\hline
\end{tabular}

Table 3 Farmer knowledge in pesticide handling, application and waste disposal

\begin{tabular}{|c|c|c|c|}
\hline Item & Response & Frequency & Percentage (\%) \\
\hline \multirow{2}{*}{ Pest control training } & Yes & 7 & 5.80 \\
\hline & No & 113 & 94.2 \\
\hline \multirow[t]{3}{*}{ Observing safety interval } & & 83 & 69.2 \\
\hline & Yes & & \\
\hline & No & 37 & 30.8 \\
\hline \multirow{2}{*}{$\begin{array}{l}\text { Reading label on pesticide } \\
\text { container }\end{array}$} & Yes & 89 & 74.2 \\
\hline & No & 31 & 25.8 \\
\hline \multirow{7}{*}{$\begin{array}{l}\text { Use of protective equipment } \\
\text { items }\end{array}$} & Nose guards & 21 & 17.5 \\
\hline & Boots & 13 & 10.8 \\
\hline & Gloves & 11 & 9.20 \\
\hline & Coveralls & 09 & 7.50 \\
\hline & Goggles & Nil & Nil \\
\hline & Headgear & Nil & Nil \\
\hline & None & 66 & 55.0 \\
\hline \multirow{4}{*}{$\begin{array}{l}\text { Mode of disposing of } \\
\text { pesticides }\end{array}$} & Incineration & Nil & Nil \\
\hline & Inside house & 09 & 7.50 \\
\hline & Inside store & 16 & 13.3 \\
\hline & Careless - thrown away & 95 & 79.2 \\
\hline
\end{tabular}

\subsection{Different storage conditions of treated crops}

In majority of the families $(67.5 \%)$ that stored crops for consumption, the crops were treated with pesticides to avoid insect damage. 32.5\% of the families that did not store their crops sold the crops while they were still in the farm. The most common method for storing crops was via hanging in the house and smoking $(80 \%)$. Some crops were preserved in sealed bins $(10.8 \%)$, although this was limited due to the high cost and lack of bulk storage capacity. A rare storage method consisting of hermetically sealing the crops in underground pits was practiced by a minority of the farmers (9.20\%). This storage method constituted the "other" methods of storage (Table 4).

Table 4. Different storage methods of treated crops

\begin{tabular}{clcc}
\hline \multicolumn{1}{c}{ Item } & \multicolumn{1}{c}{ Response } & Frequency & Percentage (\%) \\
\hline Crop storage after harvest & Yes & 81 & 67.5 \\
& No & 39 & 32.5 \\
Storage facilities & Traditional granary & Nil & Nil \\
& Hanging in house and & & \\
& smoking & 96 & 80.0 \\
& Sealed bins & 13 & 10.8 \\
& Others & 11 & 9.20 \\
\hline
\end{tabular}

\subsection{Processing methods used to remove pesticide residues from crops before consumption}

Water washing was the most consistent method of crop processing to remove pesticide residue (77.5\%), followed by removing the outer layer (22.5\%) prior to cooking or consumption (Table 5). 
Hulling and detergent washing of crops before cooking or consumption were not reported in the study area.

Table 5. Processing methods used to remove pesticide residue from crops before consumption

\begin{tabular}{lcc}
\hline \multicolumn{1}{c}{ Processing method } & Frequency & Percentage (\%) \\
\hline Hulling & Nil & Nil \\
Water washing & 93 & 77.5 \\
Detergent washing & Nil & Nil \\
Removing outer layer & 27 & 22.5 \\
\hline
\end{tabular}

\subsection{Adverse effect of pesticide exposure to humans and the environment}

Approximately $59.2 \%$ of all the families confirmed that they observed health problems related to pesticide exposure, while $40.8 \%$ reported no cases of illness related to pesticides (Table 6). Major symptoms such as headache (30.8\%), wheezing (25.8\%), dizziness $(24.2 \%)$ and skin problems $(19.2 \%)$ were commonly diagnosed in the homesteads. Neurological system disturbances, diarrhea and vomiting were not registered in the study area. A majority of the families (59.2\%) observed environmental changes after application of pesticides while $40.8 \%$ did not observe any changes in the environment. These environmental changes include damage of non-target plants (49\%) and disappearance of insects $(51 \%)$.

Table 6. Adverse effect of pesticides on humans and the environment

\begin{tabular}{llll}
\hline \multicolumn{1}{c}{ Item } & Response & Frequency & Percentage (\%) \\
\hline Adverse effects due to pesticides & Yes & 71 & 59.2 \\
application on crop & No & 49 & 40.8 \\
& Skin problems & 23 & 19.2 \\
& neurological system & Nil & Nil \\
& disturbances & Nil & Nil \\
Symptoms of these adverse & diarrhea & Nil & Nil \\
effects & vomiting & 37 & 30.8 \\
& headache & 29 & 24.2 \\
& dizziness & 31 & 25.8 \\
Environnemental change after & Yheezing & 71 & 59.2 \\
pesticides application. & No & 49 & 40.8 \\
& & & \\
Explanation & Damage of non-target & 73 & 49.0 \\
& plants & & \\
& Disappearance of insects & 77 & 51.0 \\
\hline
\end{tabular}

\section{Discussion}

The current studied the different factors related to safe practice in using pesticides at work and home. 120 farm workers participated in the study. The knowledge level of the participants in relation to demographics and the interpersonal factors included practices of the use of pesticide among the farm workers were examined. The high levels of participation in the questionnaire interview compared to those reported in Lebanon (Salameh et al., 2004) and Brazil (Recena et al., 2006) indicate high levels of farmers' interest in the study. Majority of the participants had low educational background; $71 \%$ of males and $59.2 \%$ of females received only primary education, $49 \%$ of males and $40.8 \%$ of females received secondary education, and none of both sexes received tertiary education. These results were similar to those reported in different developing countries 
such as Ecuador (Hurtig et al., 2003), Brazil (Oliveira-Silva et al., 2001) and Ethiopia (Mekonnen and Agonafir, 2002). It is well-known that education level is critical to farm workers. Farmers with lower formal education levels are at higher risk of hazardous exposure to pesticides because of their inability to understand the instructions and safety procedures presented on the labels of pesticide products. These results suggest that education level in farm workers is very important to understand and prevent the health hazards associated with pesticide use in human health. These findings were similar to those reported by Atreya (2007) and Oliveira-Silva et al. (2001). The lack of education furthermore puts farm workers at severe health risks due to lack of correct knowledge on use of protective equipment, personal hygiene practice as well as recognition of early symptoms resulting from overexposure to different pesticides. Lack of knowledge prevents farmers from receiving early first aid treatment. WHO (1991) recommends that pesticides be used by trained personnel only. In this study, 55\% of the workers did not use any protective measures to decrease their exposure levels to the different pesticides used in the farm. Consequently, they were at increased risk of the health hazards associated with pesticide exposure. It was reported that the use of gloves reduced exposure to pesticides in farm workers compared to workers that did not use gloves (Woodruff et al., 1994). The use of different protective measures decreases the risk of health hazards associated with pesticide use. Following this, a study by Chen et al. (1998) reported that safety educational programs decreased the prevalence of pesticide poisoning from $1.05 \%$ to $0.25 \%$ in Chinese farm workers.

In the current study, $67.5 \%$ of the families used pesticides for the treatment of stored crops intended for consumption to prevent insect infestation. $80 \%$ of the farmers used hanging and smoking treatments on the stored crops at home. This storage treatment may result in exposure of children as well as adults to risks associated pesticide exposure (Jallow et al., 2017). More than $77 \%$ of the farmers reported that they used water washing to remove pesticides form stored crops. It is well known that washing is a common practice for the removal of pesticide residues from produce (Batzer et al., 2002; Akgun Karabulut et al., 2001). However, some pesticides can penetrate into the grains over time (Yang et al., 2016a.b, 2017) and cannot be eliminated from the stored crops via water washing (Soliman, 2001).

The current results indicate that numerous health problems arise from farmer exposure to pesticides. Major symptoms such as headaches $(30.8 \%)$, wheezing $(25.8 \%)$, dizziness $(24.2 \%)$ and skin problems $(19.2 \%)$ were commonly diagnosed in the homesteads, revealing significant pathological problems due to the pesticide-treated crops. Most of these problems result from a lack of knowledge on safe handling, formulation and application of pesticides by farmers, as evidenced by the lack of protective measures (Zalom, 2001). The majority of families $(59.2 \%)$ observed an environmental change after application of pesticides while $40.8 \%$ did not observe any changes in the environment. These environmental changes include damage of non-target plants (49\%) and disappearance of insects (51\%). It was reported that over $98 \%$ of sprayed insecticides and $95 \%$ of sprayed herbicides reach destinations other than their target destinations in air, water, bottom sediments and food (Okello and Okello, 2010). The results of the current study are in agreement with previous studies suggesting that most occupational exposure to pesticides is from inhalation or skin absorption which occurs when farm workers are not aware (Yang et al., 2016 a,b).

\section{Conclusion}

The study carried out shows that farmers in Bambili have low knowledge levels concerning the safe use and handling of pesticides in relation to their own health and their consumers' health. Water washing was the most consistent method observed for crop cleaning procedure followed by removing the outermost layer prior to cooking or consumption. Major symptoms such as headache, wheezing, dizziness and skin problems were commonly diagnosed in the homesteads. Majority of the families observed clear environmental changes after the application of pesticides. The results of this survey provides data that may be useful in formulating policies aimed at safe handling, application and storage of pesticides to reduce health hazards to the farmer and consumer. Special educational programs and legislation to promote the safe use of pesticides as well as the application 
of personal protective measures are highly needed to decrease exposure of farm workers in Bambili to pesticides.

\section{References}

[1] Akgun Karabulut, O., Lurie, S., Droby, S., 2001. Evaluation of the use of sodium bicarbonate, potassium sorbate and yeast antagonists for decreasing postharvest decay of sweet cherries. Postharvest Biol. Technol. 23 (3), 233-236.

[2] Atreya, K., 2007. Pesticide use knowledge and practices: gender differences in Nepal. Environ. Res. 104(2), 305-311.

[3] Batzer, J.C., Gleason, M.L., Weldon, B., Dixon, P.M., Nutter, F.W.J., 2002. Evaluation of postharvest removal of sooty blotch and flyspeck on apples using sodium hypochlorite, hydrogen peroxide with peroxyacetic acid, and soap. Plant Dis. 86 (12), 1325-1332.

[4] Cha, E.S., Hwang, S.S., Lee, W.J., 2014. Childhood leukemiamortality and farming exposure in South Korea: a national population-based birth cohort study. Cancer Epidemiol. 38, 401-407.

[5] Chen, S., He, F., Zhang, Z., Gao, Y., Zhou, A., Xie, C., Xiong, L., Chen, D., Wang, S., Jia, J.,1998. Evaluation of a safety educational programme for the prevention of pesticide poisoning. Med. Lav. 89(Suppl 2), S91-98.

[6] Damalas, C.A., Koutroubas, S.D., 2016. Farmers' exposure to pesticides: toxicity types and ways of prevention. Toxics 4, 1-10.

[7] Das, S., Bagchi, A., Gangopadhay, S., Ghosh, S., 2016. Work related health disorders of female agricultural workers correlated with sawing and ploughing in Bengal: an ergonomic profile. Int. J. Current Res. Acad. Rev. 4, 155-166.

[8] Focho, D.A., Newu, M.C., Anjah, M.G., Nwana, F.A., Ambo, F.B., 2009. Ethnobotanical survey of trees in Fundong, Northwest Region, Cameroon. J. Ethnobiol. Ethnomed. 5, 17-21.

[9] Gay L. R., 1992. Educational Research: Competences for analysis and application (3 ${ }^{\text {rd }}$ ed) Paris: Merrill.

[10] Gimou, M.-M.; Charrondiere, U.R.; Leblanc, J.C.; Pouillot, R. Dietary exposure to pesticide residues in Yaoundé: The Cameroonian total diet study. Food Addit. Contam. 2008, 25, 458-471.

[11] Grung, M., Lin, Y., Zhang, H., Ste en, A.O., Huang, J., Zhang, G., et al., 2015. Pesticide levels and environmental risk in aquatic environments in China- a review. Environ. Int. 81, 87-97.

[12] Hurtig, A.K., San Sebastián, M., Soto, A., Shingre, A., Zambrano, D., Guerrero, W., 2003. Pesticide use among farmers in the Amazon basin of Ecuador. Arch. Environ. Health. 58(4), 223-228.

[13] ILO, 2011. Safety and health in agriculture. Research Report. Labour Protection Department, International Labour Organization, Switzerland

[14] Jallow, M.F., Awadh, D.G., Albaho, M.S., Devi, V.Y., Thomas, B.M., 2017. Pesticide knowledge and safety practices among farm workers in Kuwait: results of a survey. Int. J. Environ. Res. Public Health 14(4), 340-354.

[15] Kaewboonchoo, O., Kongtip, P., Woskie, S., 2015. Occupational health and safety for agricultural workers in Thailand: gaps and recommendations, with a focus on pesticide use. Environ. Occup. Health Policy 25, 102-120.

[16] Kamga, A.; Kouame, C.; Tchindjang, M.; Chagomoka, T.; Drescher, A.W. Environmental impacts from overuse of chemiclas fertilizers and pesticides amongst market gardening in Bamenda, Cameroon. Rev. Sci. Tech. For. Environ. Bassin Congo 2013, 1, 6-19.

[17] Lerro, C.C., Koutros, S., Andreotti, G., Hines, C.J., Blair, A., Lubin, J., et al., 2015. Use of acetochlor and cancer incidence in the Agricultural Health Study. Int. J. Cancer 137, 1167-1175.

[18] Markel, T.A., Proctor, C., Ying, J.,Winchester, P.D., 2015. Environmental pesticides increase the risk of developing hypertrophic pyloric stenosis. J. Pediatr. Surg. 50, 1283-1288.

[19] Matthews, G.; Wiles, T.; Baleguel, P. A survey of pesticide application in Cameroon. Crop Prot. 2003, $22,707-714$. 
[20] Mekonnen, Y., Agonafir, T., 2002. Pesticide sprayers' knowledge, attitude and practice of pesticide use on agricultural farms of Ethiopia. Occup. Med. 52(6), 311-315.

[21] Mugenda O.M., Mugenda A.G., 1999. Research methods: Quantitative and qualitative approach. Pp. 15-40 ACTS Press Nairobi, (Kenya).

[22] Okello, J.J., Okello, R.M., 2010. Do EU pesticide standards promote environmentally friendly production of fresh export vegetables in developing countries? Evidence from Kenyan green bean industry. Environ. Develop. Sustain. 12(3), 341-355.

[23] Oliveira-Silva, J.J., Alves, S.R., Meyer, A., Perez, F., Sarcinelli, P.N., da Costa Mattos, R., C., Moreira, J.C., 2001. Influence of socioeconomic factors on the pesticides poisoning, Brazil. Rev. Saude Publica. 35(2), 130-135.

[24] Padilla, A., 2013. Occupational Health and Safety of Agricultural Workers: ILO Conventions and Gaps. Research Report. Pesticide Action Network Asia and the Pacific (PAN AP), Malaysia.

[25] Phung, D.T., Connell, D., Miller, G., Rutherford, S., Chu, C., 2013. Needs assessment for reducing pesticide risk: a case study with farmers in Vietnam. J. Agromedicine 18, 293-303.

[26] Pouokam, G.B., Lemnyuy, A.W., Ndikontar, A.S., Sidatt, M.E.H., 2017. A Pilot Study in Cameroon to Understand Safe Uses of Pesticides in Agriculture, Risk Factors for Farmers' Exposure and Management of Accidental Cases. Toxics. 5(4). pii: E30. doi:10.3390/toxics5040030.

[27] Recena, M.C., Caldas, E.D., Pires, D.X., Pontes, E.R., 2006. Pesticides exposure in Culturama, Brazilknowledge, attitudes, and practices. Environ Res. 102(2), 230-236.

[28] Remoundou, K., Brennan, M., Hart, A., Frewer, L.J., 2014. Pesticide risk perceptions, knowledge, and attitudes of operators, workers, and residents: a review of the literature. Hum. Ecol. Risk. Assess. 20, 1113-1138.

[29] Salameh, P.R., Baldi, I., Brochard, P., Abi Saleh, B., 2004. Pesticides in Lebanon: a knowledge, attitude, and practice study. Environ. Res. 94(1), 1-6.

[30] Soliman, K.M., 2001. Changes in concentration of pesticide residues in potatoes during washing and home preparation. Food Chem. Toxicol. 39(8), 887-891.

[31] Verger, P.J.P., Boobis, A.R., 2013. Reevaluate pesticides for food security and safety. Science 341, 717-718.

[32] WHO. World Health Organization, 1991. Safe use of pesticides. Fourteenth report of the WHO expert committee on vector biology and control. World Health Organ Tech. Rep. Ser. 813, 1-27.

[33] Woodruff, T.J., Kyle, A.D., Bois, F.Y., 1994. Evaluating health risks from occupational exposure to pesticides and the regulatory response. Environ. Health Perspect. 102(12), 1088-1096.

[34] Yang, T., Zhang, Z., Zhao, B., Hou, R., Kinchla, A., Clark, J. M., He, L., 2016a. Real-Time and in situ monitoring of pesticide penetration in edible leaves by surface-enhanced raman scattering mapping. Anal. Chem. 88 (10), 5243-5250.

[35] Yang, T., Zhao, B., Hou, R., Zhang, Z., Kinchla, A. J., Clark, J. M., He, L., 2016b. Evaluation of the penetration of multiple classes of pesticides in fresh produce using surface-enhanced raman scattering mapping. J. Food Sci. 81(11), T2891-T2901.

[36] Yang, T., Zhao, B., Kinchla, A.J., Clark, J. M., He, L., 2017. Investigation of pesticide penetration and persistence on harvested and live basil leaves using surface-enhanced raman scattering mapping. J. Agric. Food Chem. 65, 3541-3550.

[37] Zalom, F.G., 2001. Pesticide use practices in integrated pest management. In: Handbook of pesticide toxicology. Academic press: New York, NY, $2^{\text {nd }}$ Edition: 275-283 